\title{
Infrared and Raman spectroscopy of non-conventional hydrogen bonding between N,N'-disubstituted urea and thiourea groups: a combined experimental and theoretical Investigation
}

Rozenn Le Parc, ${ }^{a}$ Vania T. Freitas, ${ }^{\text {ab }}$ Patrick Hermet, ${ }^{c}$ Ana M. Cojocariu, ${ }^{c d}$ Xavier Cattoën, e Hubert Wadepohl, ${ }^{f}$ David Maurin, ${ }^{a}$ Cheuk Hin Tse, ${ }^{a}$ John R. Bartlett, ${ }^{d}$ Rute A. S. Ferreira, ${ }^{b}$ Luis D. Carlos, ${ }^{b}$ Michel Wong Chi Man ${ }^{* c}$ and Jean-Louis Bantignies ${ }^{\star a}$

a Laboratoire Charles Coulomb, UMR CNRS 5221, Université de Montpellier, 34095 Montpellier, France.E-mail: jean-louis.bantignies@umontpellier.fr

${ }^{b}$ Physics Department, University of Aveiro, 3810-193 Aveiro, Portugal

c Institut Charles Gerhardt Montpellier, UMR 5253 CNRS-ENSCM-UM, 34296 Montpellier, France

' University of the Sunshine Coast, Maroochydore DC, QLD 4558, Australia

- Univ. Grenoble Alpes, CNRS, Grenoble INP, Institut Néel, 38000 Grenoble, France

${ }^{f}$ Anorganisch-Chemisches Institut der Universitaet Im Neuenheimer Feld 270, D-69120 Heidelberg, Germany

\begin{abstract}
The variety of $\mathrm{H}$ bond $(\mathrm{HB})$ interactions is a source of inspiration for bottom-up molecular engineering through self-aggregation. Non-conventional intermolecular HBs between N,NOdisubstituted urea and thiourea are studied in detail by vibrational spectroscopies and ab initio calculations. Raman and IR mode assignments are given. We show that it is possible to study selectively the different intermolecular bifurcated intra- and inter-dimer HBs with the two types of HB acceptors. Through the ab initio calculation, the thioamide I mode, a specific marker of $\mathrm{N}-\mathrm{H} \cdots \mathrm{S}=\mathrm{C} \mathrm{HB}$ interactions, is unambiguously identified.
\end{abstract}

\section{Introduction}

Hydrogen bonding (HB) has long been noted as a powerful organizing force in molecular crystals ${ }^{1,2}$ and biopolymers. ${ }^{3}$ Intermolecular hydrogen bonds in urea and thiourea derivatives control the self-aggregation of these moieties, leading to a variety of structures that inspire nanomaterial engineering. ${ }^{2-8}$ The urea group is a well-known, robust building block that forms persistent $\mathrm{N}-\mathrm{H} \cdots \mathrm{O}$ HBs in a variety of environments. In particular, N,NO-disubstituted ureas are known to form onedimensional hydrogenbonded chains by employing their two $\mathrm{N}-\mathrm{H}$ proton donors and the $\mathrm{C}=\mathrm{O}$ proton acceptor in bifurcated HBs, ${ }^{1}$ the highest electron density being maximum on an axial position around the carbonyl bond. ${ }^{4,5}$ Consequently, adjacent urea groups in the chain prefer being coplanar, with HBs in the plane defined by the oxygen lone pairs leading predominantly to trans-trans conformations. ${ }^{6}$ The resulting one-dimensional chains are present in many crystals. 1 Therefore, conventional strong and predictable oxygencentered HB interactions (OCHB) in urea derivatives are classically used for the synthesis of crystalline solids ${ }^{7}$ with various architectures, 3 from one-dimensional chains and nanotubes, ${ }^{8}$ to layered and three-dimensional frameworks. ${ }^{9,10}$ Thiourea derivatives have been far less used as design elements in crystal engineering ${ }^{1}$ despite the fact that they can also self-organize by $\mathrm{N}-\mathrm{H} \cdots \mathrm{S}=\mathrm{C}$ hydrogen-bonding. ${ }^{11}$ The sulfurcentered hydrogen bonding (SCHB) interactions are considered as nonconventional in nature. Indeed, the thiocarbonyl group is a weaker HB acceptor than the carbonyl one, but this is compensated by the stronger acidity of the $\mathrm{N}-\mathrm{H}$ donors in 
thioureas. ${ }^{12}$ Furthermore, it is also reported that the SCHB interaction is not purely electrostatic but is also an admixture of electrostatic, dispersion, polarization, and covalent interactions. ${ }^{13}$ In the crystalline state, N,N'-disubstituted thioureas can be encountered either in a trans-trans conformation as in the corresponding urea groups, or in a cis-trans conformation. The energy difference in the gas phase between the two forms was calculated to be only $1 \mathrm{kcal} \mathrm{mol}^{-1}$ for dimethylthiourea. ${ }^{14}$ In the transtrans conformation, thioureas can form bifurcated hydrogen-bonded chains which exhibit a zigzag shape in which two thioureas are almost orthogonal to each other due to the sideway approach of the $\mathrm{N}-\mathrm{H}$ donors to the thiocarbonyl acceptor. ${ }^{7}$ Thioureas in the cis-trans conformation can self-associate into dimers in the solid state, via two complementary $\mathrm{N}-\mathrm{H} \cdots \mathrm{S} \mathrm{HBs}$ formed between two thioureas leading in this case to a cyclic HB.15 Indeed, even if the $\mathrm{H}$-bonding networks in thiourea derivatives are much more variable, they also play a key role in the construction of nanostructured materials, and in crystal assemblies. ${ }^{1,11}$

To date, HB interactions of N,NO-disubstituted urea groups with analogous thioureas have not been well described in the literature. Indeed, to the best of our knowledge, only complex structures developed for asymmetric organocatalysis have been previously reported ${ }^{16,17}$ where the urea $\mathrm{N}-\mathrm{H}$ groups were made strongly acidic by the presence of trifluoromethylarene substituents. ${ }^{18}$ Investigation of the nonconventional HB interactions between ureas and thioureas (UTHB) with regards to their self-assembling properties is therefore required. Vibrational spectroscopies are powerful tools to identify robust markers of specific HB interactions, with numerous experimental and theoretical studies of vibrations of hydrogen bonds having thus been reported for urea and thiourea systems. ${ }^{19-21}$ We recently synthesized a model compound (MUT) featuring urea and thiourea groups linked through a 1,4-phenylene spacer (Scheme 1), showing the capability of such systems to self-assemble through UTHBs. In this work, we performed comprehensive infrared and Raman investigations, coupled with density functional calculations, to probe the sensitivity of the vibrational dynamics to mixed urea and thiourea hydrogen bonding in MUT. We show that it is possible to study specifically and independently the two types of UTHBs, bifurcated intra- and inter-dimer HBs, encountered in this molecular compound.

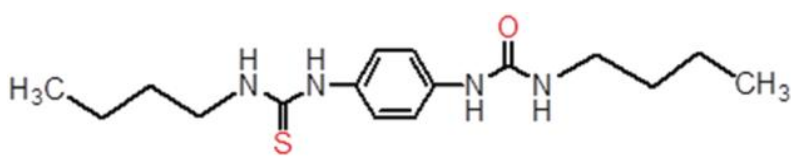

Scheme 1 Schematic representation of the structure of the MUT molecule.

\section{Materials and methods}

\section{Synthesis}

The organic model MUT (Scheme 1) was prepared by reaction of 1,4diaminobenzene with one equivalent of butyl isothiocyanate, followed by condensation of the mono-adduct obtained with butyl isocyanate, as detailed elsewhere. ${ }^{22}$

\section{Infrared spectroscopy}

Fourier transform infrared (FT-IR) spectroscopy measurements were performed under vacuum using a Bruker IFS $66 \mathrm{~V}$ spectrometer equipped with a $\mathrm{N}_{2}$-cooled mercury cadmium telluride (MCT) detector, a Globar source, and a potassium bromide 
$(\mathrm{KBr})$ beam splitter. The measurements were performed in the mid-infrared region $\left(400-5000 \mathrm{~cm}^{-1}\right)$ in the transmission configuration using $\mathrm{KBr}$ pellets $(0.8 \mathrm{mg}$ sample/300 mg KBr), prepared under 8-tons pressure. Prior to recording the spectra, the pellets were dried at $100{ }^{\circ} \mathrm{C}$ for about $20 \mathrm{~h}$, to reduce the levels of adsorbed water. The spectral resolution was $4 \mathrm{~cm}^{-1}$, and 64 scans were co-added for each spectrum. Low-temperature measurements between room temperature and $10 \mathrm{~K}$ were performed using a helium-cooled cryostat. Solutions of $30 \mathrm{mg}$ of MUT dissolved in $1 \mathrm{~mL}$ of THF were studied in transmission configuration in cells (CaF2 windows) with thickness ranging from $13 \mathrm{~mm}$ to $1 \mathrm{~mm}$.

\section{Raman spectroscopy}

Raman spectra were measured at room temperature using a Renishaw Invia spectrometer. For spectra in the range $100-1800 \mathrm{~cm}^{-1}$ the $785 \mathrm{~nm}$ excitation line was chosen to avoid any luminescence (laser power 5\%, $150 \mathrm{~s}$ integration) with a 1200 lines grating providing a resolution close to $1 \mathrm{~cm} \_1$. In the range $2700-3600 \mathrm{~cm}^{-1}$, excitation at $532 \mathrm{~nm}$ was used with 2400 lines grating providing a resolution close to $0.8 \mathrm{~cm}^{-1}$.

\section{Computational details}

Density functional theory (DFT) based calculations on a MUT single crystal were performed using the VASP package $\mathrm{e}^{23-25}$ and the generalized gradient approximation to the exchange correlation functional as proposed by Perdew, Burke and Ernzerhof. ${ }^{26}$ We used as input the structure previously refined in ref. 22. Interactions between ions and electrons were described by the projector augmented wave method in the real space representation. The electronic wave functions were expanded in planewaves up to a kinetic energy cut-off of $460 \mathrm{eV}$ and integrals over the Brillouin zone were approximated by sums over a $6 \times 4 \times 2$ mesh of special k-points following the Monkhorst-Pack scheme. ${ }^{27}$ For the structural relaxation, experimental lattice parameters were fixed and only the atomic positions were relaxed by using a fine integration grid until the maximum residual atomic force was less than $6 \times 10^{-3} \mathrm{eV} \AA^{-1}$. The zone-center dynamical matrix was calculated within the harmonic approximation by finite difference of the Hellmann-Feynman forces using an atomic displacement of $0.03 \mathrm{~A}$. Positive and negative displacements were used to minimize the anharmonic effects. Born effective charges were computed using the linear response. The infrared absorption spectra and the different bonding contributions were calculated following the methodology described in ref. 28.

\section{Results and discussion}

The crystalline structure described previously ${ }^{22}$ shows that two different $\mathrm{HB}$ interactions are involved in the self-assembling of MUT (Fig. 1). Urea and thiourea groups form well-aligned dimers through bifurcated intermolecular UTHBs. The zigzag shape is exhibited for inter-dimer UTHB involving a $\mathrm{C}=\mathrm{S}$ proton acceptor. ${ }^{7}$

Within the dimer, a HB labelled DB occurs between the $\mathrm{N}-\mathrm{H}$ protons of thiourea groups and the oxygen from urea groups as proton acceptors, while two adjacent dimers are linked together through inter-dimer HB (IB) between the $\mathrm{N}-\mathrm{H}$ protons of urea groups and the sulfur from thiourea groups as proton acceptors (Fig. 1). 


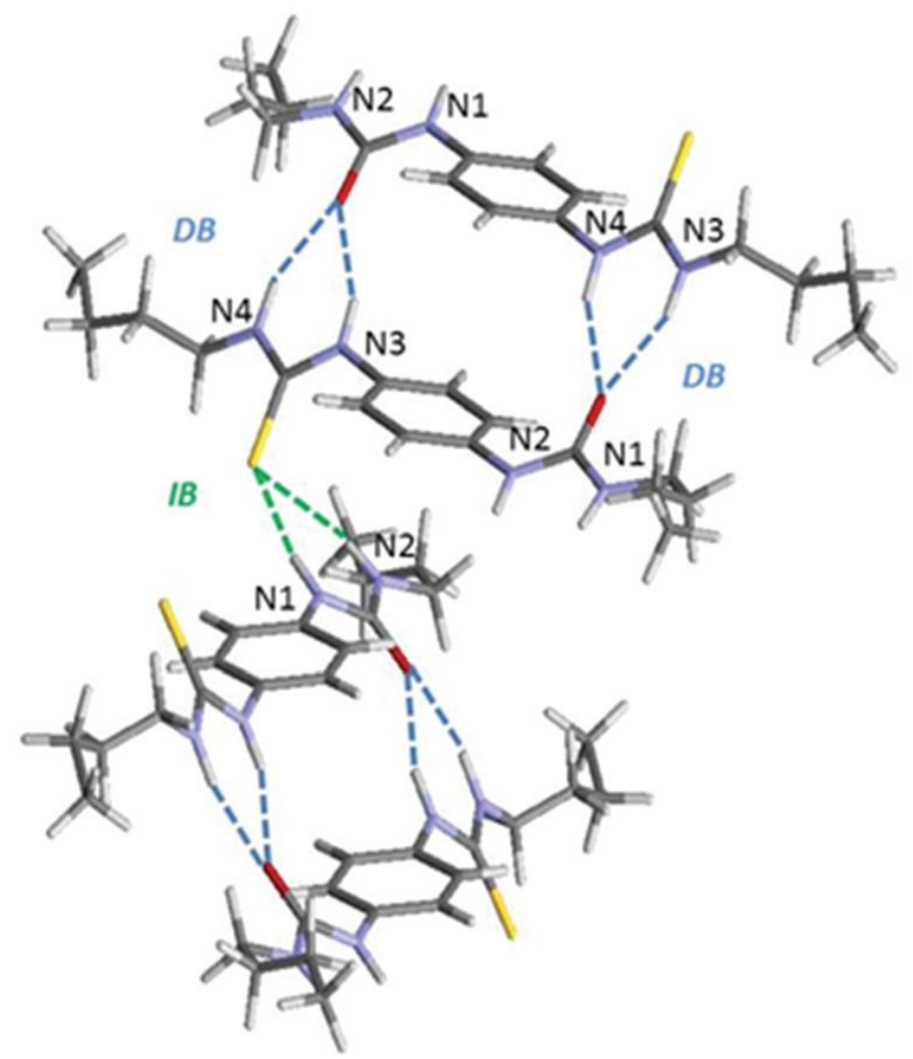

Fig. 1 Local hydrogen bondings within the MUT single crystal from the DFT relaxed structure. The bifurcated DB bond shows O-N distances, respectively, equal to $2.82 \AA$ for O-N3 (1.858 $\AA$ for O-H3) and $2.91 \AA$ for O-N4 (1.976 $\AA$ for O-H4). The asymmetric bifurcated IB bond shows S-N distances, respectively, equal to $3.30 \AA$ for S-N2 (2.312 $\AA$ for S-H2) and $3.50 \AA$ for S-N1 (2.648 $\AA$ for S-H1).

In our calculations the relaxed $\mathrm{O} \cdots \mathrm{N}$ distance in the bifurcated $\mathrm{DB}$ bond and the $\mathrm{S} \cdots \mathrm{N}$ distance in the asymmetric bifurcated IB bond are in excellent agreement with

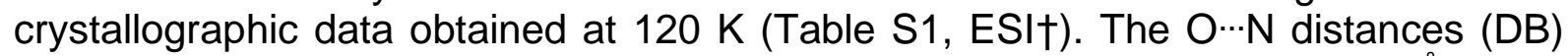
obtained from calculation (resp. experimental) are on average around $2.87 \AA$ (resp. $2.87 \AA$ ) whereas the average $\mathrm{S} \cdots \mathrm{N}$ distances (IB) from calculation reach $3.40 \AA$ (resp. $3.43 \AA$ ). Within the dimer, the carbon-carbon distance between urea and thiourea groups is $4.5 \AA$, which is the classical urea ___ urea intermolecular spacing of $\sim 4.6 \AA$ observed for bifurcated hydrogen-bonded chains in trans-trans conformation. ${ }^{1}$

Experimental IR and Raman spectra in the regions of the amide vibrations are displayed in Fig. 2-4. Corresponding calculated IR spectra and Raman mode positions are also given while the vibrational dynamics of MUT is discussed below.

\section{Amide I and II region (1400-1700 $\left.\mathrm{cm}^{-1}\right)$}

The excellent agreement of both the positions and relative intensities of the IR bands observed between the experimental spectra at $10 \mathrm{~K}$ and the calculated one within the $1400-1700 \mathrm{~cm}^{-1}$ range (Fig. 2(i)) allows an unambiguous assignment of the vibrational features (Table 1). A projection of the specific oscillator strength associated with the $\mathrm{C}=\mathrm{S}, \mathrm{C}=\mathrm{O}$ and $\mathrm{N}-\mathrm{H}$ bonds (Fig. $\mathrm{S} 1, \mathrm{ESI}+$ ) is also consistent with the assignments. The amide I band may be considered to be comprised of contributions from mainly $v(C=O)$ stretching coupled with $v(\mathrm{C}-\mathrm{N})$ and $\delta(\mathrm{C}-\mathrm{C}-\mathrm{N})$ vibrations. ${ }^{29}$ This mode is conformationally sensitive due to dipole-dipole coupling of the carbonyl groups. The wavenumber of this band, sensitive to $\mathrm{H}$ bonding involving the carbonyl group, has 
been used extensively to differentiate between the different conformations found in polypeptides and proteins. ${ }^{30,31}$
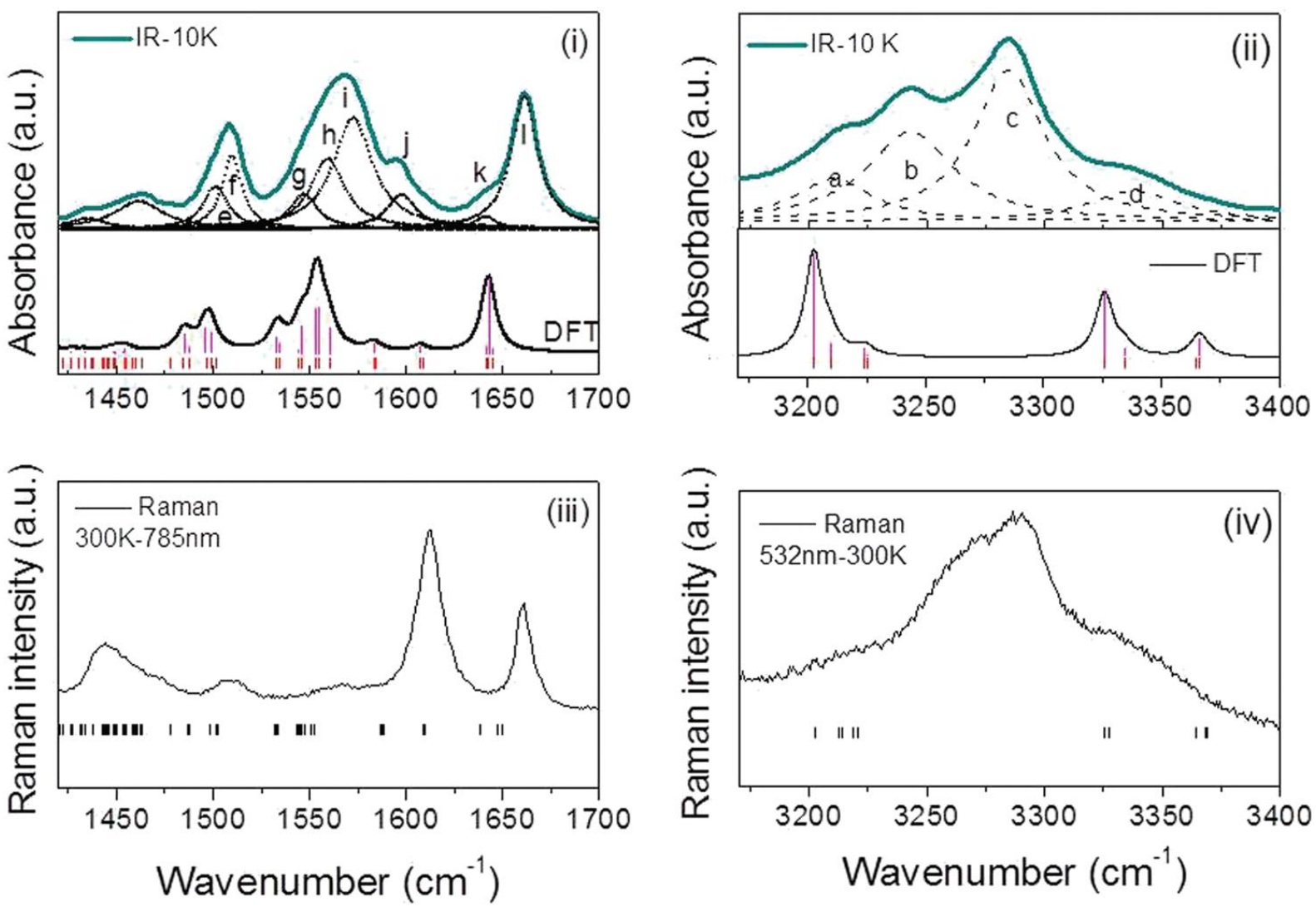

Fig. 2 Measured $(10 \mathrm{~K})$ and calculated infrared spectra for MUT located in the region of amide I and amide II (i) and in the region of amide A (ii). The deconvolutions of the experimental spectra at $10 \mathrm{~K}$ are obtained using Lorenzian bands. Experimental Raman spectra located in the region of amides I and II (iii) and amide A (iv) with calculated wavenumbers of Raman modes shown by vertical lines.

In MUT, amide I at $1661 \mathrm{~cm}^{-1}$ ( $i$ component) is only sensitive to DB. Beside the main amide I component, a shoulder ( $\mathrm{k}$ ) can be observed at around $1641 \mathrm{~cm}^{-1}$, assigned to $\mathrm{n}(\mathrm{C}=\mathrm{C})$ vibration of the aryl ring coupled to amide I. The amide and thioamide II modes appear at lower wavenumbers (typically $1500-1600 \mathrm{~cm}^{-1}$ ). They originate from the out-of-phase combination of the $\mathrm{N}-\mathrm{H}$ in-plane bending and the $\mathrm{C}-\mathrm{N}$ stretching vibration, with smaller contributions from the $\mathrm{C}=\mathrm{O}(\mathrm{C}=\mathrm{S}$ for thioamide) in-plane bending and the $\mathrm{C}-\mathrm{C}$ and $\mathrm{N}-\mathrm{C}$ stretching vibrations. The amide II vibration shows little conformation sensitivity; ${ }^{30}$ however for several systems, the wavenumber of this band is modified by $\mathrm{N}-\mathrm{H}^{\cdots} \mathrm{Y}$ bonding. ${ }^{32,33}$ In MUT, this broad feature between 1520 and 1620 $\mathrm{cm}^{-1}$ can be deconvoluted into four contributions (Fig. 2(i)) revealing a complex structure sensitive to both DB and IB. The (h) and (I) contributions are assigned mainly to vibrations involving both amide II and thioamide II. The $(\mathrm{g})$ contribution results only from thioamide while the (j) component is assigned to aryl coupled with thioamide. Contributions (e) and (f) observed at lower wavenumbers are ascribed to the $v(C=C)$ vibration of the aryl ring coupled with the $\delta(\mathrm{N}-\mathrm{H})$ involving either urea (e) or thiourea (f). The detailed assignments are listed in Table 1.

The Raman spectrum is also shown in Fig. 2(iii) and (iv) for comparison with the corresponding IR data. Here, the intensity of the Raman lines could not be calculated because the computational time was too high considering the large number of atoms (384) in the unit cell of MUT. By considering the number of modes and their positions, 
it appears that the vibrational dynamics in this domain are rather similar in term of active modes. However, significant differences are observed in their intensities (oscillator strength for infrared and variation in polarizability for Raman). The amide I responses in Raman and IR are similar whereas the amide II bands appear with very low Raman intensity. The main Raman peak at $1610 \mathrm{~cm} \_1$ is ascribed to a $\mathrm{C}=\mathrm{C}$ stretchingmode in the aryl ring (see assignment in Table S2, ESI†). Similarly, vibrations between 1420 and $1480 \mathrm{~cm} \_1$, assigned mainly to $\mathrm{d}(\mathrm{C}-\mathrm{H})$, also exhibit strong intensities. This illustrates the complementarity of Raman and IR dynamics for MUT.

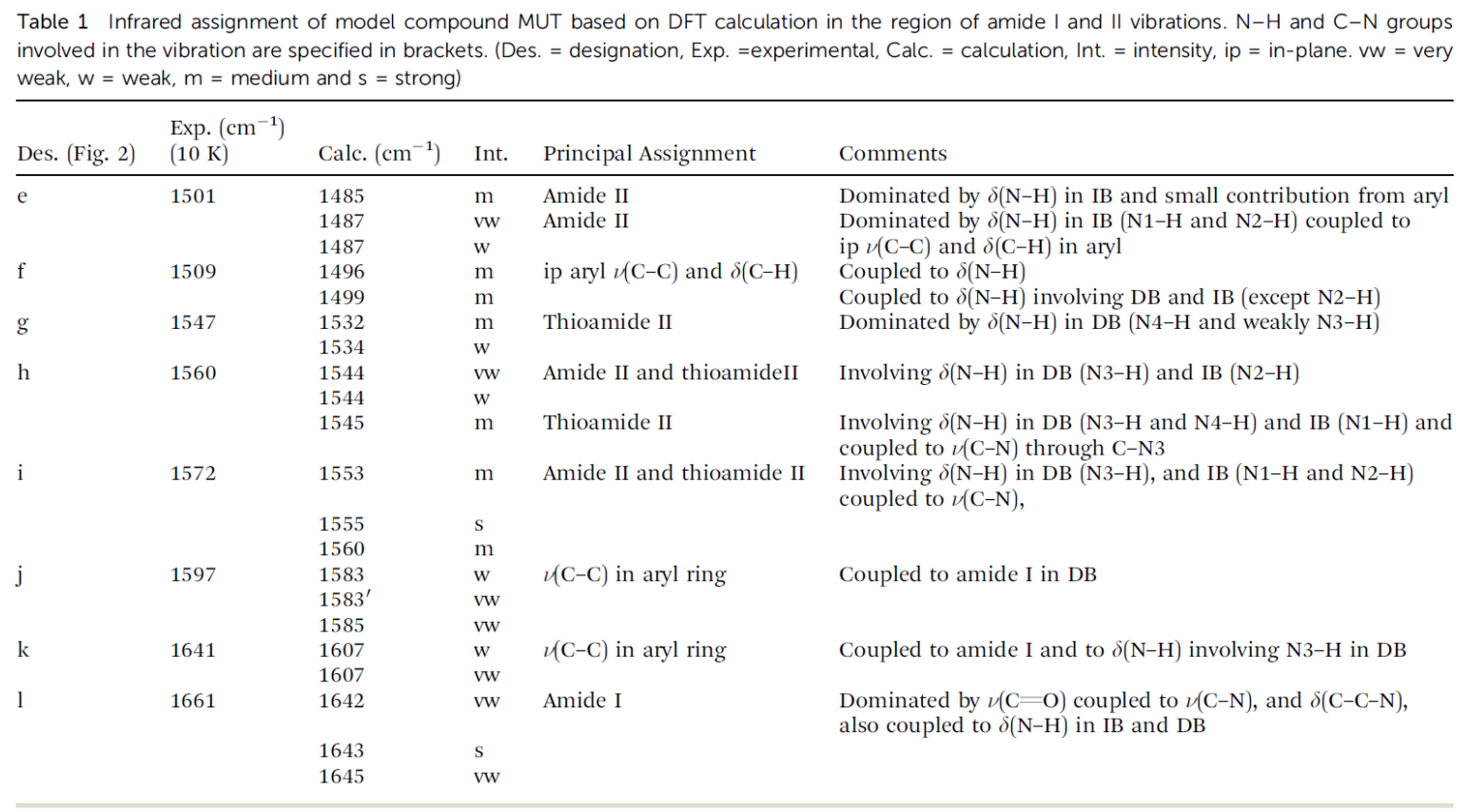

It is interesting to note that when MUT is dissolved in THF, the amide I component (I) upshifts from 1661 to $1705 \mathrm{~cm}^{-1}$, in agreement with the DFT prediction for an isolated UT molecule (Fig. 3(i) and (ii)). In THF, DB and IB bonds are expected to be cleaved, and hence $\Delta v$ amide $\mathrm{I}=44 \mathrm{~cm}^{-1}$ is representative of DB dimer dissociation. For the main amide/thioamide II band, a red shift from 1570 to $1531 \mathrm{~cm}^{-1}$ is observed in THF, suggesting cleaved HB associated with both thiourea and urea species. In contrast, the features (e), (f), (j) and (k) all coupled to or dominated by aryl vibrations are weakly affected by the dissolution in THF, as expected. Our results indicate that the amide I band is a remarkable marker of the DB. We show further that its counterpart for IB interactions is obtained from the low wavenumber domain (see the $500-700 \mathrm{~cm}^{-1}$ range).

\section{$v(\mathrm{~N}-\mathrm{H})$ stretching region $\left(3000-3400 \mathrm{~cm}^{-1}\right)$}

In the $3000-3400 \mathrm{~cm}^{-1}$ range, the amide A profile is dominated by $v(\mathrm{~N}-\mathrm{H})$ vibrations. They may be considered as a first approximation to be isolated modes and normal coordinate calculations of polyamides and polypeptides indicate that the potential energy distribution is essentially composed of this stretching motion. ${ }^{34}$ Accordingly, they are not conformation-sensitive modes. Nevertheless $\mathrm{X}-\mathrm{H} \cdots \mathrm{Y}$ HB interactions are characterized by weakening of the $\mathrm{X}-\mathrm{H}$ bond which causes elongation of this bond and a shift of the $v(\mathrm{X}-\mathrm{H})$ mode to lower wavenumbers. ${ }^{35-37}$ This red shift is often considered as an indicator of the strength of HBs. For MUT, the profile of the amide and thioamide 
A regions reveals a complex, broad experimental feature very similar for both Raman (Fig. 2(iv)) and infrared (Fig. 2(ii)). The infrared spectral profile at $10 \mathrm{~K}$ is well deconvoluted using four contributions respectively labelled (a), (b), (c), and (d) with maxima at $3210,3242,3284$ and $3338 \mathrm{~cm}^{-1}$, respectively, allowing a qualitative comparison with the four main components predicted by calculation.
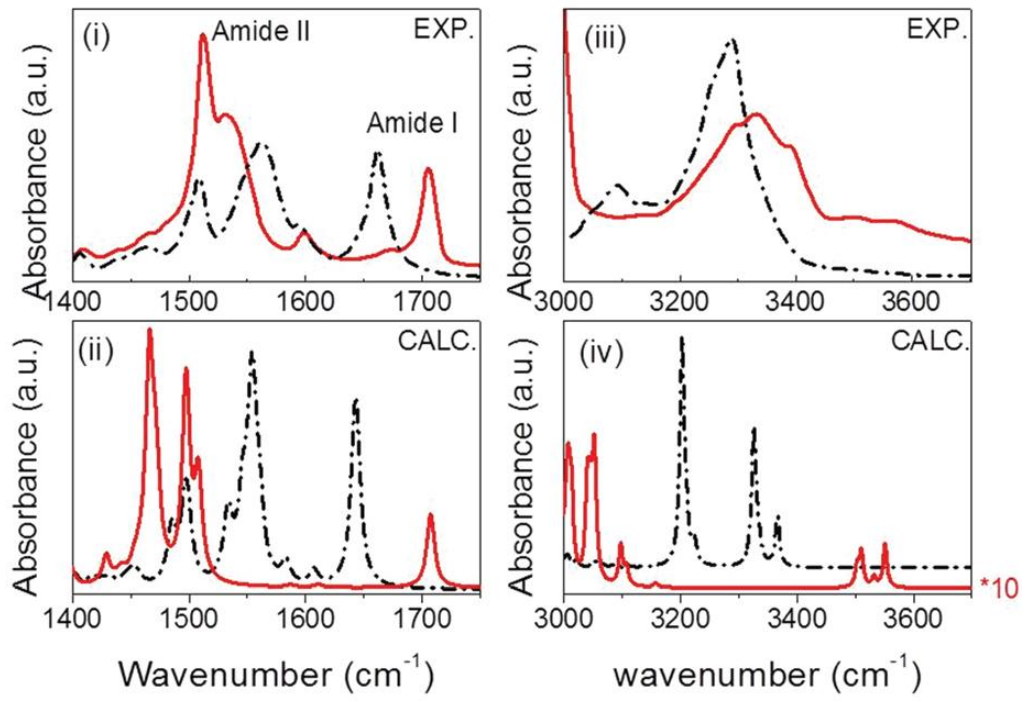

Fig. 3 Infrared spectra showing the amide I and II (i) and amide A (iii) regions in the UT crystal (dash dots) and for molecules in THF solution (solid line), compared to spectra generated by DFT (ii) and (iv) for MUT crystals (dash dots) and isolated MUT molecules (solid line).

The complete assignment for the amide A region is summarized in Table 2. Despite a significant up-shift often observed in the high wavenumber range and related to anharmonicity, ${ }^{38}$ the two experimental components at higher wavenumbers (c and d) show a good agreement, in both relative intensity and $\Delta v$, with the calculated values. The strongest contribution (c) involves a symmetric stretching $v(\mathrm{~N}-\mathrm{H})$ in thiourea (thioamide A) and this vibration is associated with DB bonds. A symmetric stretch $v(\mathrm{~N}-$ $\mathrm{H}$ ) in urea associated with IB bonds (amide A) gives rise to the contribution (d). It is evident that the component related to the strongest HB interaction (DB) appears at lower wavenumber exhibiting stronger mode oscillator strength than the component related to the longest IB bond. Lower-energy contributions ( $a$ and $b$ ), can also be reasonably assigned from the calculation, despite a poorer agreement. These two contributions are assigned to antisymmetric wavenumber $v(\mathrm{~N}-\mathrm{H})$ simultaneously involving urea and thiourea. It is noteworthy that $\mathrm{DB}$ and IB interactions can be probed separately from high wavenumber $\mathrm{n}(\mathrm{N}-\mathrm{H})$ mode study.

Table 2 Infrared assignment of model compound MUT based on DFT calculation in the region of amide A vibrations. The $\mathrm{N}-\mathrm{H}$ group involved in the vibration is specified in brackets. (Des. = designation, Exp. $=$ experimental, Calc. $=$ calculation, Int. $=$ intensity, $\mathrm{w} w=$ very weak, $\mathrm{w}=\mathrm{weak}, \mathrm{m}=\mathrm{medium}$ and $\mathrm{s}=\mathrm{strong}$ )

\begin{tabular}{|c|c|c|c|c|c|}
\hline Des. (Fig. 3) & $\begin{array}{l}\text { Exp. }\left(\mathrm{cm}^{-1}\right) \\
(10 \mathrm{~K})\end{array}$ & Calc. $\left(\mathrm{cm}^{-1}\right)$ & Int. & Principal assignment & Comments \\
\hline \multirow[t]{4}{*}{$\mathrm{a}, \mathrm{b}$} & \multirow[t]{4}{*}{3210,3242} & 3202 & $\mathrm{~s}$ & \multirow[t]{4}{*}{ Amide $\mathrm{A}$ and thioamide $\mathrm{A}$} & Antisymmetric $\nu(\mathrm{N}-\mathrm{H})$ mixing IB $(\mathrm{N} 2-\mathrm{H})$ and $\mathrm{DB}(\mathrm{N} 3-\mathrm{H})$ \\
\hline & & 3209 & $\mathrm{w}$ & & Antisymmetric $\nu(\mathrm{N}-\mathrm{H})$ involving IB $(\mathrm{N} 2-\mathrm{H})$ \\
\hline & & 3224 & $\mathrm{w}$ & & Antisymmetric $\nu(\mathrm{N}-\mathrm{H})$ mixing IB $(\mathrm{N} 2-\mathrm{H})$ and $\mathrm{DB}(\mathrm{N} 3-\mathrm{H})$ \\
\hline & & 3254 & $\mathrm{vw}$ & & Antisymmetric $\nu(\mathrm{N}-\mathrm{H})$ involving $\mathrm{DB}(\mathrm{N} 3-\mathrm{H})$ \\
\hline \multirow[t]{3}{*}{$\mathrm{c}$} & \multirow[t]{3}{*}{3284} & 3325 & $\mathrm{w}$ & \multirow[t]{3}{*}{ Thioamide A } & Symmetric $\nu(\mathrm{N}-\mathrm{H})$ involving DB $(\mathrm{N} 3-\mathrm{H})$ \\
\hline & & 3326 & $\mathrm{vw}$ & & Symmetric $\nu(\mathrm{N}-\mathrm{H})$ involving $\mathrm{DB}(\mathrm{N} 4-\mathrm{H})$ \\
\hline & & 3334 & $\mathrm{~m}$ & & Symmetric $\nu(\mathrm{N}-\mathrm{H})$ involving $\mathrm{DB}(\mathrm{N} 3-\mathrm{H}$ and weak $\mathrm{N} 4 \mathrm{H})$ \\
\hline \multirow[t]{3}{*}{$\mathrm{d}$} & \multirow[t]{3}{*}{3338} & 3365 & $\mathrm{vw}$ & \multirow[t]{3}{*}{ Amide A } & Symmetric $\nu(\mathrm{N}-\mathrm{H})$ involving IB $(\mathrm{N} 1-\mathrm{H})$ \\
\hline & & $3366 \mathrm{a}$ & $\mathrm{vw}$ & & \\
\hline & & $3366 \mathrm{~b}$ & $\mathrm{w}$ & & \\
\hline
\end{tabular}




\section{Thioamide $I$ and amide $V$ domain $\left(500-800 \mathrm{~cm}^{-1}\right)$}

Like amide I, one would expect to find the equivalent "thioamide I" vibration involving $v(\mathrm{C}=\mathrm{S})$ for thioureas. It is expected at lower wavenumber than the amide I due to the mass of sulfur $(\mu \mathrm{CO} / \mu \mathrm{CS}=0.78)$. The $v(\mathrm{C}=\mathrm{S})$ mode has been the subject of debates for decades in the literature. Its IR active mode position is given near $700 \mathrm{~cm}^{-1}, 39,40$ $1100-1200 \mathrm{~cm}^{-1} 41$ and $1300-1400 \mathrm{~cm}^{-1} .42,43$ The wavenumber of this vibrational mode is thought to be strongly influenced by the substituents ${ }^{44-46}$ and partial coupling effects have also been described. ${ }^{40,41,47-49}$ By comparing the relevant regions of the experimental and the calculated IR spectra, Fig. 4(i) and (ii) demonstrate that the component (q) observed at $688 \mathrm{~cm}^{-1}$ is assigned to a vibration mainly involving $v(C=S)$, without a strong coupling term between the $v(C=S)$ mode and other vibrations, unlike other modes involving $v(C=S)$ in the range $1220-1350 \mathrm{~cm}^{-1}$ are strongly coupled to $\delta(\mathrm{C}-\mathrm{H})$ vibrations. For the component $(\mathrm{q})$, only a minor contribution from the symmetric out-of-plane $\mathrm{N}-\mathrm{H}$ bend in urea and aryl vibrations is revealed. The thioamide I vibration is also accessible through Raman spectroscopy (Fig. 4(iii)), with a feature observed at $696 \mathrm{~cm}^{-1}$ (predicted between 699 and $709 \mathrm{~cm}^{-1}$ in the calculation, Table S2, ESI†) next to a very strong peak associated with the $\mathrm{C}-\mathrm{H}$ bending vibrations in aryl and butyl groups.

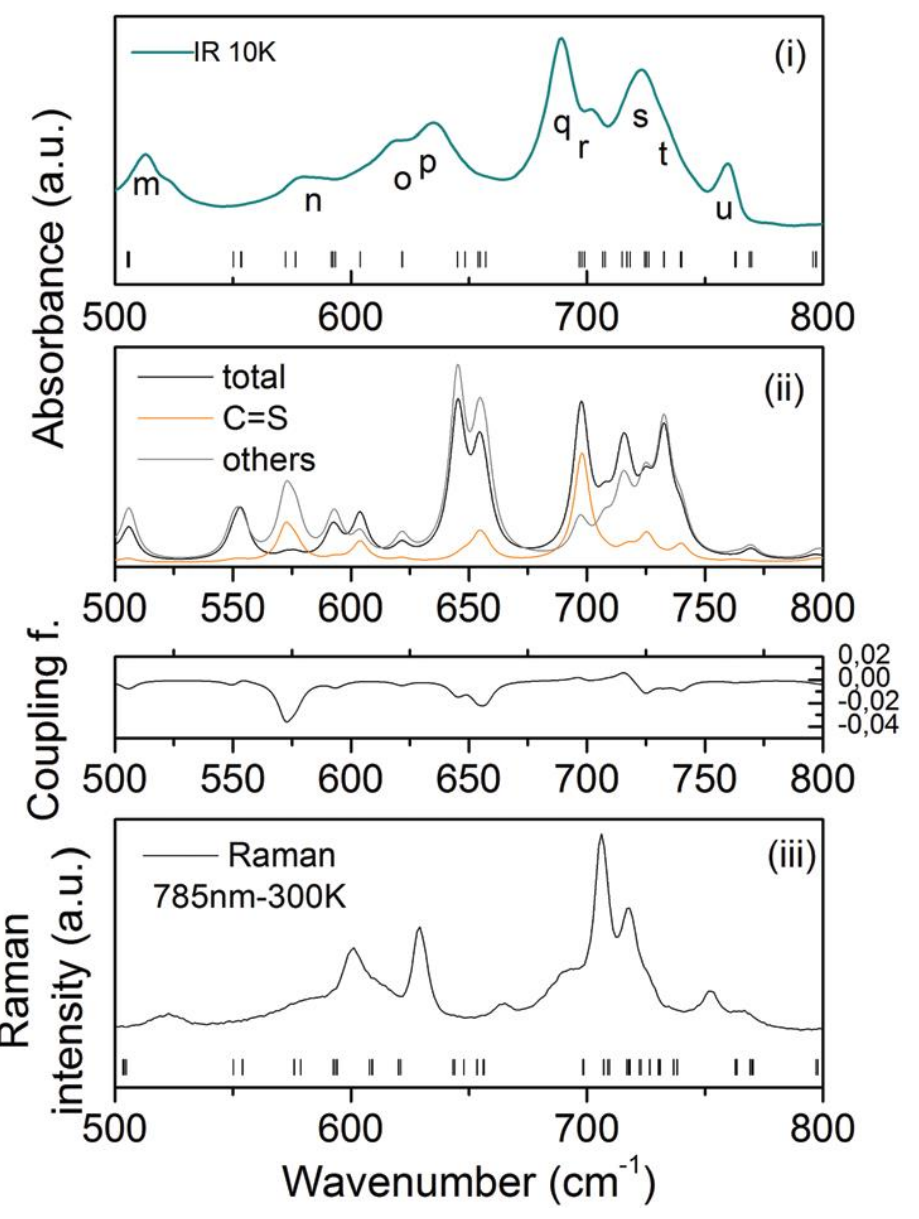

Fig. 4 Infrared spectrum showing the amide $V$ and the thioamide I vibrations at $10 \mathrm{~K}$ (i). Partial and total infrared spectra calculated from DFT showing the partial infrared spectrum projected on $\mathrm{C}=\mathrm{S}$ vibrations and other vibrations (ii). Coupling term between $\mathrm{C}=\mathrm{S}$ modes and other vibrations is shown in the lower part of Figure (ii). The Raman spectrum in the same spectral range is also shown for comparison (iii). 
The amide $\mathrm{V}$ and thioamide $\mathrm{V}$ contributions dominated by out of plane $\mathrm{N}-\mathrm{H}$ bending are also predicted in this domain (Table 3), involving IB (o and p), or DB (s) or showing a coupled involvement (t). From the calculated partial infrared spectrum, it is evident that some vibrations involving $\mathrm{C}=\mathrm{S}$ moieties are predicted at different positions between 550 and $750 \mathrm{~cm}^{-1}$ but superimposed on amide V vibrations (Fig. 4(ii)). Apart from the vibration predicted at $603 \mathrm{~cm}^{-1}$, the coupling factor between these vibrations and $\mathrm{C}=\mathrm{S}$ bond motion is negative, which induces a reduction in the corresponding band intensity. In Raman spectra dominated by aryl and aliphatic $\mathrm{C}-\mathrm{H}$ vibrations, amide $\mathrm{V}$ features exhibit weak intensities (Fig. 4(iii)).

\begin{tabular}{|c|c|c|c|c|c|}
\hline Des. (Fig. 4) & $\begin{array}{l}\text { Exp. }\left(\mathrm{cm}^{-1}\right) \\
(10 \mathrm{~K})\end{array}$ & Calc. $\left(\mathrm{cm}^{-1}\right)$ & Int. & Principal assignment & Comments \\
\hline & & 495 & $\mathrm{w}$ & $\delta(\mathrm{C}-\mathrm{H})$ & Involving butyl \\
\hline & & 505 & $\mathrm{~m}$ & $\delta(\mathrm{C}-\mathrm{H})$ & Involving aryl \\
\hline $\mathrm{m}$ & 512 & 550 & $\mathrm{~m}$ & & Asymmetric oop N-H bending involving IB (N2-H and N1-H) \\
\hline \multirow[t]{2}{*}{$\mathrm{n}$} & 579 & 592 & $\mathrm{~m}$ & & Asymmetric $\omega(\mathrm{N}-\mathrm{H})$ involving $\mathrm{DB}(\mathrm{N} 3-\mathrm{H})$ \\
\hline & & 603 & $\mathrm{~m}$ & & \\
\hline \multirow[t]{2}{*}{$\mathrm{o}, \mathrm{p}$} & 620,635 & 645 & $\mathrm{~s}$ & Amide $\mathrm{V}$ & Symmetric oop N-H bending involving IB (N1-H and N2-H) \\
\hline & & 654 & $\mathrm{~s}$ & & coupling with aryl $\delta(\mathrm{CC})$ \\
\hline \multirow[t]{3}{*}{$\mathrm{q}, \mathrm{r}$} & 689,702 & 696 & $\mathrm{~s}$ & Thioamide I & $\begin{array}{l}\nu(\mathrm{C}=\mathrm{S}) \text { coupling with a weak symmetric } \mathrm{N}-\mathrm{H} \text { bending, } \\
\text { involving IB and coupling with aryl } \delta(\mathrm{CC})\end{array}$ \\
\hline & & 697 & $\mathrm{~m}$ & & \\
\hline & & 698 & vw & & \\
\hline \multirow[t]{11}{*}{$\mathrm{s}, \mathrm{t}, \mathrm{u}$} & $722,734,760$ & 714 & $\mathrm{~s}$ & Thioamide V & $\begin{array}{l}\text { Symmetric oop } \mathrm{N}-\mathrm{H} \text { bending involving } \mathrm{DB}(\mathrm{N} 3-\mathrm{H} \text { and } \mathrm{N} 4-\mathrm{H}) \\
\text { and coupling } \delta(\mathrm{C}-\mathrm{H}) \text { from butyl }\end{array}$ \\
\hline & & 717 & $\mathrm{~s}$ & & \\
\hline & & 718 & $\mathrm{vw}$ & & \\
\hline & & 724 & w & $\begin{array}{l}\text { Amide } \mathrm{V} \text { and } \\
\text { thioamide } \mathrm{V}\end{array}$ & $\begin{array}{l}\text { Symmetric oop N-H bending involving DB }(\mathrm{N} 4-\mathrm{H}) \text { and } \omega(\mathrm{N}-\mathrm{H}) \\
\text { bending involving IB (N1-H and N2-H) }\end{array}$ \\
\hline & & 725 & $\mathrm{w}$ & & \\
\hline & & 726 & $\mathrm{vw}$ & & \\
\hline & & 732 & $\mathrm{~s}$ & & \\
\hline & & 739 & $\mathrm{~m}$ & Thioamide V & $\begin{array}{l}\text { Symmetric oop N-H bending involving DB (N3-H and N4-H) } \\
\text { and coupling } \delta(\mathrm{C}-\mathrm{H})\end{array}$ \\
\hline & & 740 & $\mathrm{w}$ & & \\
\hline & & 763 & $\mathrm{nw}$ & Amide VI & ip $\delta(\mathrm{N}-\mathrm{C}=\mathrm{O})$ strongly attenuated by coupling from butyl \\
\hline & & 770 & w & $\delta(\mathrm{C}-\mathrm{H})$ & \\
\hline
\end{tabular}

The infrared spectrum for MUT in solution is not available in this spectral range as a consequence of solvent absorption.

However, it is possible to predict the behavior of both the thioamide I and the amide $\mathrm{V}$ vibrations in solution using DFT by comparing the spectra for an isolated MUT molecule and a MUT crystal (Fig. 5).

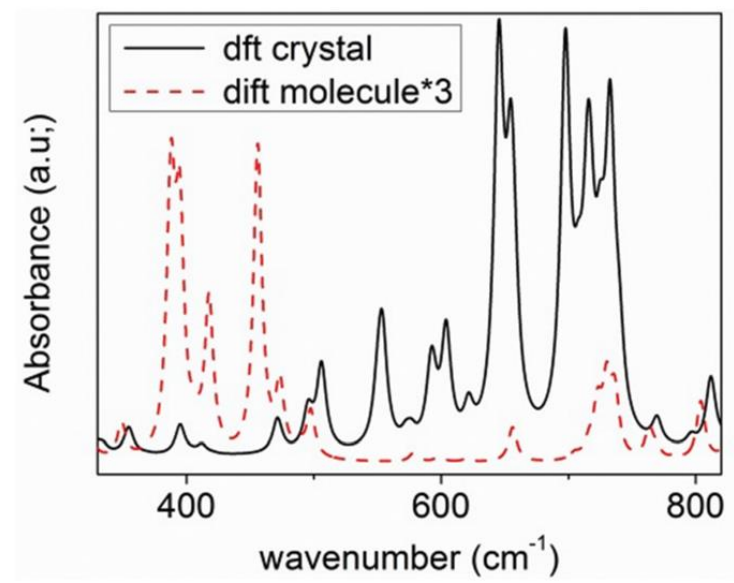

Fig. 5 Calculated spectra for the MUT crystal and isolated UT molecule, in the domains of amide V, thioamide $\mathrm{V}$ and thioamide I. 
Upon breaking the IB bond, the thioamide I mode is significantly affected, with the mode position (t) shifting from 696 to 705 and $730 \mathrm{~cm}^{-1}$. The amide $V$ and thioamide $\mathrm{V}$ contributions are also strongly impacted by the loss of HB interactions. They are drastically shifted from the range [640-750] to [350-500] $\mathrm{cm}^{-1}$ in agreement with the previous observation by Fillaux in uracil.50

We therefore unambiguously assigned the internal complex thioamide I mode to be sensitive to IB interactions in MUT. Amide $\mathrm{V}$ vibrations can also be assigned as markers for either IB or DB bonding. Moreover, we predict, from DFT calculations, a strong dependence of the wavenumber of $n(C=S)$ and amide $\mathrm{V}$ on $\mathrm{H}$ bonding. These vibrations are therefore promisingmarkers of the formation of these UTHBs.

\section{Conclusions}

Raman and infrared spectroscopies coupled to DFT calculations have been used to probe urea-thiourea $\mathrm{H}$ bonding in a model compound, MUT. A detailed assignment of the vibrational features of MUT is given. We show that it is possible to differentiate specific HB markers for the two different urea-thiourea intermolecular interactions identified in MUT: an intra-dimer HB involving vibrational dynamics associated with $\mathrm{C}=\mathrm{O} \cdots \mathrm{N}-\mathrm{H}$ groups and an interdimer $\mathrm{HB}$ associated with CQS $\cdots \mathrm{N}-\mathrm{H}$ groups. Our results indicate that the amide I band is a remarkable marker of the intra-dimer interaction (DB) whereas the thioamide I mode around $688 \mathrm{~cm}^{-1}$ is a marker of the inter-dimer (IB) interaction. Additional markers of the specific HB interactions are found at high wavenumbers among $v(\mathrm{~N}-\mathrm{H})$ symmetrical stretching modes (amide $\mathrm{A}$ ). We show the sensitivity of these specific vibrational markers to DB and IB dissociation. We also highlight the complementarity of Raman and infrared spectroscopies for probing intermolecular interactions. Amide II and V modes exhibit respectively strong (poor) IR (Raman) activities and aryl and $\mathrm{C}-\mathrm{H}$ vibrations strong (moderate) Raman (IR) activities. Overall, this vibrational study on the urea-thiourea interactions gives new robust spectroscopic markers to underpin the design of new $\mathrm{H}$-bond based supramolecular structures and understanding $\mathrm{H}$-bonding activation, for example in organocatalysis.

\section{Acknowledgements}

This work has been supported by Franco-Portuguese bilateral programs: PCP Pessoa, LUSO, and PICS from CNRS. We thank The IRRAMAN platform of the University of Montpellier for providing access to the IR and Raman apparatus. This work was developed within the scope of the project CICECO-Aveiro Institute of Materials, $\mathrm{POCI}$ 01-0145-FEDER-007679 (FCT Ref. UID/CTM/50011/2019), financed by FCT/MEC and the Franco- Portuguese bilateral programs: PCP Pessoa, LUSO, and PICS from CNRS. VTF acknowledges FCT for the SFRH/BD/87403/2012 grant and Campus France for the 812632A Eiffel grant.

\section{Notes and references}

1 G. E. Schultz and R. H. Schirmer, Principles of Protein Structure, Springer-Verlag, New York, US, 1979.

2 G. R. Desiraju, Angew. Chem., 2011, 50(1), 52-59.

3 S. Arnott, S. D. Dover and A. Elliott, J. Mol. Biol., 1967,30, 201.

4 R. Custelcean, Chem. Commun., 2008, 295-307.

5 R. Custelcean, N. L. Engle and P. V. Bonnesen, CrystEngComm, 2007, 9, 452-455. 
6 F. Lortie, S. Boileau and L. Bouteiller, Chem. - Eur. J., 2003, 9, 3008.

7 X. Zhao, Y.-L. Chang, F. W. Fowler and W. Lauher, J. Am. Chem. Soc., 1990, 112, 6627.

8 J. J. E. Moreau, L. Vellutini, M. Wong Chi Man, C. Bied, J.-L. Bantignies, P. Dieudonne and J.-L. Sauvajol, J. Am. Chem. Soc., 2001, 123, 7957-7958.

9 J.J.E. Moreau, L. Vellutini, M. Wong Chi Man and C. Bied, Chem. - Eur. J., 2003, 9(7), 1594-1599.

10 E. Christ, C. Blanc, A. Al Ouahabi, D. Maurin, R. Le Parc, J.-L. Bantignies, J.-M. Guenet, D. Collin and P. Mesini, Langmuir, 2016, 32, 4975-4982.

11 M. Obrzud, M. Rospenk and A. Koll, Phys. Chem. Chem. Phys., 2014, 16, 3209-3219.

12 F. G. Bordwell, D. J. Algrim and J. Harrelson, J. Am. Chem. Soc., 1988, 110, 5903.

13 S. Bhattacharyya, V. Prakash Roy and S. Wategaonkar, J. Phys. Chem. A, 2016, 120, 6902-6916.

14 R. Custelcean, M. G. Gorbunova and P. V. Bonnesen, Chem. - Eur. J., 2005, 11, 1459-1466.

15 S. Rashdan, M. E. Light and J. D. Kilburn, Chem. Commun., 2006, 4578-4580.

16 N. Probst, A'. Madara'sz, A. Valkonen, I. Pa'pai, K. Rissanen, A. Neuvonen and P. M. Pihko, Angew. Chem., 2012, 51, 8495-8499.

17 C. R. Jones, G. Dan Pantos, A. J. Morrison and M. D. Smith, Angew. Chem., 2009, 48, 7391-7394. 18 A. J. Neuvonen, T. Földes, A. Madara'sz, I. Pa'pai and P. M. Pihko, ACS Catal., 2017, 7(5), 32843294.

19 D. N. Lande, M. N. Shewale and S. P. Gejji, J. Phys. Chem. A, 2017, 121(19), 3792-3802.

20 C. F. Araujo, J. A. P. Coutinho, M. M. Nolasco, S. F. Parker, P. J. A. Ribeiro-Claro, S. Rudic', B. I. G. Soares and P. D. Vaz, Phys. Chem. Chem. Phys., 2017, 19, 17998-18009.

21 X. Chen, C. Sun, S. Wu and D. Xue, Phys. Chem. Chem. Phys., 2017, 19, 8835-8842.

22 V. T. Freitas, PhD thesis, University of Aveiro, Université de Montpellier, 2016, 233-234.

23 G. Kresse and J. Furthmüller, Phys. Rev. B: Condens. Matter Mater. Phys., 1996, 54, 11169.

24 G. Kresse and J. Furthmüller, Comput. Math. Sci., 1996, 6, 15-50.

25 G. Kresse and J. Hafner, Phys. Rev. B: Condens. Matter Mater. Phys., 1993, 47, 558.

26 J. P. Perdew, K. Burke and M. Ernzerhof, Phys. Rev. Lett., 1996, 77, 3865-3868.

27 H. J. Monkhorst and J. D. Pack, Phys. Rev. B: Condens. Matter Mater. Phys., 1976, 13, 5188.

28 A. Belhboub, P. Hermet, L. Alvarez, R. Le Parc, S. Rols, A. C. Lopes Selvati, B. Jousselme, Y. Sato, K. Suenaga, A. Rahmani and J.-L. Bantignies, J. Phys. Chem. C, 2016, 120, 28802-28807.

29 B. A. Kolesov, Spectrochim. Acta, Part A, 2017, 179, 216-220.

30 A. Barth, Biochim. Biophys. Acta, 2007, 1767, 1073-1101.

31 A.-W. Dzwolak, M. Kato and Y. Taniguchi, Biochim. Biophys. Acta, 2002, 1595, 131-144.

32 G. Creff, B. P. Pichon, C. Blanc, D. Maurin, J.-L. Sauvajol, C. Carcel, J. J. E. Moreau, P. Roy, J. R.

Bartlett, M. Wong Chi Man and J.-L. Bantignies, Langmuir, 2013, 29, 5581-5588.

33 J. J. E. Moreau, B. P. Pichon, M. Wong Chi Man, C. Bied, H. Pritzkow, J.-L. Bantignies, P.

Dieudonné and J.-L. Sauvajol, Angew. Chem., 2003, 116(2), 205-208.

34 L. R. Schroeder and S. L. Cooper, J. Appl. Phys., 1976, 47, 4310-4317.

35 E. Arunan, G. R. Desiraju, R. A. Klein, R. A. Sadlej, S. Scheiner, I. Alkorta, D. C. Clary, R. H. Crabtree, J. J. Dannenberg, P. Hobza, H. G. Kjaergaard, A. C. Legon, B. Mennucci and D. J. Nesbitt, Pure Appl. Chem., 2011, 83(8), 1619-1636.

36 S. Scheiner, Hydrogen Bonding. A theoretical perspective, Oxford University Press, NewYork, US, 1997.

37 S. Scheiner, J. Phys. Chem. B, 2005, 109(33), 16132-16141.

38 R. Le Parc, P. Hermet, S. Rols, D. Maurin, L. Alvarez, A. Ivanov, J. M. B. Quimby Caitlin Hanley, L. T. Scott and J.-L. Bantignies, J. Phys. Chem. C, 2012, 116(47), 25089-25096.

39 K. Jensen and P. Nielsen, Acta Chem. Scand., 1966, 20, 597-629.

40 D. Hadz"i, J. Kidrič., V. Knez"evic and B. Barlic", Spectrochim. Acta, Part A, 1976, 32(4), 693-704.

41 K. Srinivasana, S. Gunasekaranb and S. Krishnana, Spectrochim. Acta, Part A, 2010, 75, 11711175.

42 H. W. Thompson, D. L. Nicolson and L. N. Short, Discuss. Faraday Soc., 1950, 9, 222-235.

43 H. M. Randall, N. Fuson, R. G. Fowler and J. R. Dangl, infrared determination of organic structures, Van Nostrand, New York, 1949.

44 D. M. Wiles, B. A. Gingras and T. Suprunchuk, Can. J. Chem., 1967, 45, 469-472.

45 M. H. Hussain and E. J. Lien, Spectrosc. Lett., 1973, 6(2), 97-102.

46 C. N. R. Rao and R. Venkataraghavan, Spectrochim. Acta, Part A, 1962, 18, 541-547.

47 J. E. Stewart, J. Chem. Phys., 1957, 26, 248-254.

48 V. Z. Vassileva and P. P. Petrova, Croat. Chem. Acta, 2005, 78, 295-299.

49 R. K. Gosavi, U. Agarwal and C. N. R. Rao, J. Am. Chem. Soc., 1967, 89(2), 235-239.

50 F. Fillaux and C. De Loze, J. Chim. Phys., 1976, 73, 1004-1009. 